\title{
Oxygen glow discharge cleaning in nuclear fusion devices
}

\author{
C. Hopf*, W. Jacob, V. Rohde \\ Max-Planck-Institut für Plasmaphysik, EURATOM Association, Boltzmannstr. 2, 85748 Garching, Germany
}

\begin{abstract}
Laboratory experiments were carried out as part of the preparations of an oxygen glow discharge cleaning experiment in ASDEX Upgrade. They aimed at evaluating the effect of mixing the oxygen with helium, the collateral damage caused by the glow discharge, as well as the influence of impurities in the films being eroded. Oxygen concentrations below $20 \%$ in helium are sufficient to achieve high erosion rates. The discharge can lead to the formation of oxide layers on surfaces which — as demonstrated for tungsten — can be rapidly reduced by post-treatment in a hydrogen discharge. For carbon, aluminum and iron the physical sputtering yield may become similar to the erosion yield of redeposited layers, but it is by more than one order of magnitude smaller for tungsten. Using a-B:C:H films with varying boron content, it was found that impurities can cause the erosion rate to drop by orders of magnitude.
\end{abstract}

Published with Journal of Nuclear Materials: Received 9 August 2007
Accepted for publication 1 October 2007
Available online 23 October 2007
Published 15 March 2008
J. Nucl. Mater. 374 (2008) 413-421
doi: $10.1016 /$ j.jnucmat.2007.10.001

\section{INTRODUCTION}

The present selection of first-wall materials in ITER includes carbon fibre composite (CFC) at the divertor strike points. With this choice, erosion and redeposition of carbon accompanied by codeposition of hydrogen isotopes is expected to be one of the dominant tritium retention mechanisms [1-3]. As there will be strict safety limits, control of the tritium inventory will be mandatory. To this end, techniques for regular tritium removal are urgently required [1-3]. As one among several options [1,4], oxygen glow discharges have been proposed $[5,6]$ as a means of detritiation. The technique was tested in several tokamaks [7-10].

The erosion of carbon in oxygen plasmas is a standard method for etching processes in semiconductor fabrication [11-13] as well as the cleaning of surfaces from carbon impurities $[14,15]$. Landkammer et al. [16, 17] and Jacob et al. [6] systematically studied the erosion of amorphous hydrocarbon films (a-C:H) in oxygen plasmas. Their major results were: The achievable erosion rates in an oxygen plasma are by far higher than the rates expected from physical sputtering and high compared with hydrogen plasmas. The erosion rate increases with substrate temperature, but this dependence is rather weak in the range between 300 and $625 \mathrm{~K}$, meaning that no elevated temperatures are required for satisfactory efficiency. The erosion rate also increases with ion energy, which was varied by varying the substrate bias voltage. By using different mixtures of oxygen and noble gases they showed that the composition of the ion flux to the surface-i. e., the ratio of oxygen to noble gas ions-has only a minor effect on the rate as long as the supply of neutral oxygen is sufficient. Landkammer and Jacob concluded from their results that oxygen plasma erosion of carbon is a two-step process in which

*Corresponding author, e-mail: Christian.Hopf@ipp.mpg.de energetic ions damage the surface and predominantly neutral oxygen species react to form $\mathrm{CO}, \mathrm{CO}_{2}, \mathrm{H}_{2} \mathrm{O}$ and $\mathrm{H}_{2}$. Vietzke et al. [18] first demonstrated the existence of a synergism between energetic ions-in their experiment $\mathrm{Ar}^{+}$- and molecular oxygen. This synergism was recently investigated more thoroughly by Hopf et al. [19]. The latter results are an indication that $\mathrm{O}_{2}$ might be the most important chemically reactive species in low-temperature oxygen plasma erosion of carbon.

The major advantages of low-temperature oxygen plasma cleaning in a tokamak are that-as opposed to the thermal combustion of the redeposited layers in oxygen-no elevated temperatures are required, that simple means of plasma generation can be used such as DC [7, 10, 20] or ion cyclotron resonance $[9,21,22]$ glow discharges and that high rates are achievable. The mentioned laboratory studies focussed on the erosion of laboratory-deposited a-C:H under controlled conditions. In addition, a number of issues are especially relevant to the application in a tokamak:

1. For a number of reasons, mixtures of $\mathrm{He} / \mathrm{O}_{2}$ are preferred in DC glow discharges in tokamaks. The erosion rate will depend on the mixture ratio.

2. Redeposited layers in tokamaks are not well-defined amorphous hydrogenated films like those produced under controlled laboratory conditions, but contain varying amounts of impurities and may be structurally different, which can have influence on the erosion rate.

3. The interaction of the oxygen-containing glow discharge with the first wall may have side effects such as excessive retention of oxygen, collateral damage on as sensitive parts as diagnostic mirrors, etc.

These issues will be addressed in the present article. 


\section{EXPERIMENTAL}

Two different plasma chambers were used for the experiments. One was an electron cyclotron resonance (ECR) plasma setup [16]. An ECR discharge is generated in a cylindrical metallic cage inside the vacuum chamber. The plasma expands toward the sample holder through a hole in the bottom plate of the cage. An additional DC self-bias of up to $\approx 400 \mathrm{~V}$ can be achieved at the sample holder by applying a capacitively coupled RF voltage.

Using hydrocarbon gases for plasma generation, amorphous hydrogenated carbon films $(\mathrm{a}-\mathrm{C}: \mathrm{H})$ can be deposited with varying properties from so-called soft to hard films [23]. These films are used to study their erosion in oxygencontaining plasmas in the same device.

Provided the sample is reflective (usually a silicon wafer is used as substrate), erosion and deposition can be monitored by real-time in-situ ellipsometry at a wavelength of $632.8 \mathrm{~nm}$ yielding information on erosion and deposition rates as well as optical properties of the films. Advantages of the ECR setup are the wide range of accessible discharge parameters, i.e. pressure, gas mixture ratios, substrate bias, etc. and the insitu rate measurement. Additional diagnostics such as residual gas mass spectrometry and optical emission spectroscopy can be attached if required. Details of the setup can be found in reference [16].

In parallel, experiments were carried out in a device which resembles the glow discharge configuration of ASDEX Upgrade and allows to introduce used ASDEX Upgrade tiles which carry redeposits as specimens. The chamber has a total volume of $\approx 0.5 \mathrm{~m}^{3}$. The anode, which is of the same design as the glow-discharge anodes in ASDEX Upgrade, is a rod of $45 \mathrm{~cm}$ length. A grounded shield between the anode and the neighboring parts of the vessel wall avoids local discharges. The whole wall serves as cathode. The power supply provides a maximum of 2 A discharge current at typical discharge voltages of 200-400 V. The setup is also equipped with a differentially pumped residual gas analyzer. Visual inspection of the tiles' front surface is possible through a window. We refer to this setup as GDCC (glow discharge chamber) in this article.

\section{CLEANING EFFICIENCY IN $\mathrm{O}_{2}$ /HE MIXTURES}

Helium with an admixture of a comparatively small amount of $\mathrm{O}_{2}$ is preferred to pure $\mathrm{O}_{2}$ as feed gas in DC glow discharges for the following reasons. When using oil-sealed rotary vacuum pumps the oxygen concentration in the pumped gas is a safety issue. Apart from that, the stability of a DC glow discharge sets an upper limit to the oxygen concentration. In the GDCC setup we found that $100 \% \mathrm{O}_{2} \mathrm{DC}$ discharges can hardly be ignited and cannot be sustained over extended periods of time. The oxygen concentration limit seems to depend on wall condition and is very often below $10 \%$. Helium is primarily chosen due to its small mass which causes less physical sputtering as compared with heavier noble gases. To find good operational parameters, we studied the influence of the $\mathrm{O}_{2} / \mathrm{He}$ mixture ratio on the erosion rate.

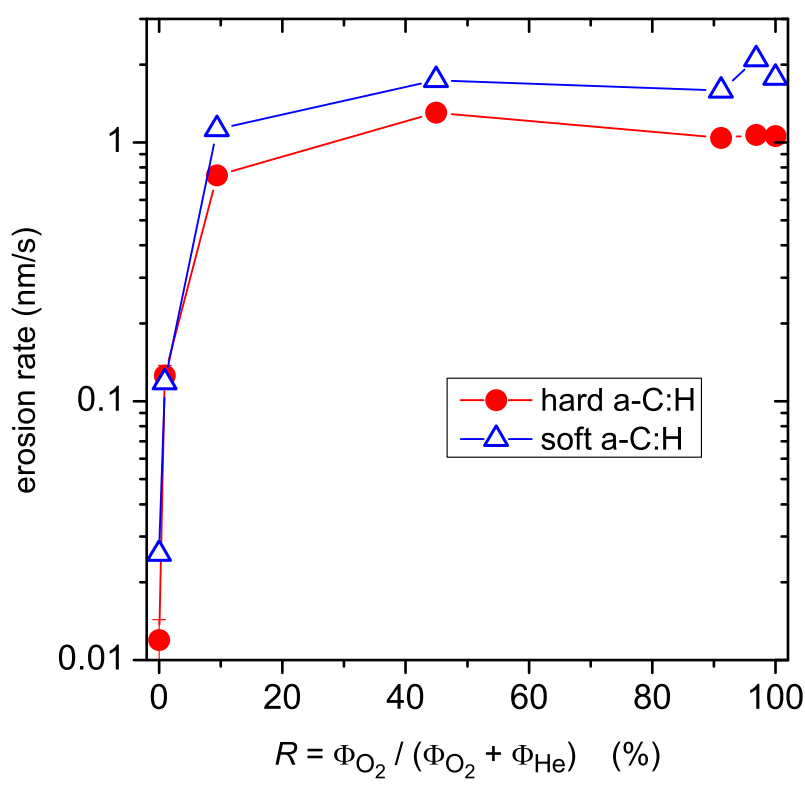

FIG. 1: Erosion rate of soft and hard a-C:H films in a $\mathrm{He} / \mathrm{O}_{2}$ ECR plasma with additional $-400 \mathrm{~V}$ substrate bias as a function of the $\mathrm{O}_{2} /\left(\mathrm{O}_{2}+\mathrm{He}\right)$ gas flow ratio. The total pressure and absorbed microwave power were held constant at $p=0.5 \mathrm{~Pa}$ and $P \approx 150 \mathrm{~W}$. The absolute rates for soft and hard a-C:H films should not be compared because differently sized holes in the bottom of the ECR cage were used for the two experimental series.

In order to be able to access the full range of oxygen concentrations, the experiment was carried out in the ECR setup. Soft or hard a-C:H films were deposited on silicon wafers from a methane plasma with the substrate at floating potential (several volts negative with respect to the plasma) or based to $-300 \mathrm{~V}$, respectively. Afterwards, the several hundred nanometer thick films were eroded in a plasma of a mixture of helium and oxygen, and the variation of the film thickness was monitored by in-situ ellipsometry. During erosion all external parameters except the $\mathrm{He} / \mathrm{O}_{2}$ mixture ratio were kept constant at a total pressure before plasma ignition of $0.5 \mathrm{~Pa}, 150 \mathrm{~W}$ microwave power and a substrate bias voltage of $-400 \mathrm{~V}$. The chamber was constantly pumped during the experiment and the gas flows $\phi_{i}$-controlled via mass-flow controllers-were adjusted to result in a total pressure of $0.5 \mathrm{~Pa}$ and the desired oxygen flow fraction $R=\phi_{\mathrm{O}_{2}} /\left(\phi_{\mathrm{O}_{2}}+\phi_{\mathrm{He}}\right)$. By mass spectrometry, $R$ was found to be roughly equal to the ratio $p_{\mathrm{O}_{2}} /\left(p_{\mathrm{O}_{2}}+p_{\mathrm{He}}\right)$ of partial pressures with a maximal deviation of 0.05 at $R \approx 0.5$.

Figure 1 shows the resulting erosion rates as a function of $R$. For both types of films, there is a huge difference of about two orders of magnitude between physical sputtering in a pure He discharge $(R=0)$ and chemical sputtering in $\mathrm{O}_{2}$ plasmas at sufficiently high $R$. Interestingly, the erosion rate saturates already at around $10 \% \mathrm{O}_{2}$. This early saturation is primarily a consequence of the fact that only as much oxygen is needed as to be able to react at all ion-induced damage sites [16, 17]. In typical DC glow discharges the ion flux density towards the 


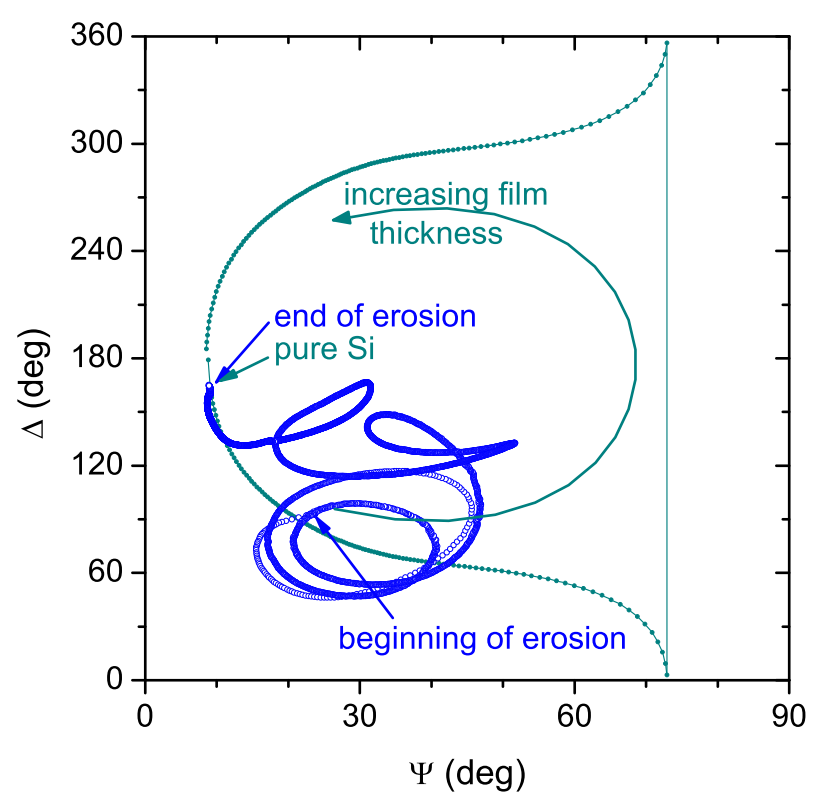

FIG. 2: Ellipsometric angles as measured during the erosion of an ASDEX Upgrade redeposit on a silicon wafer (big open circles, appearing as thick line) and as expected for erosion of a soft a-C:H film on $\mathrm{Si}$ (small, line-connected solid circles). Between two neighboring points of the a-C:H model curve there is a difference of the film thickness of $1 \mathrm{~nm}$.

surface will be even lower compared with the ECR discharge. In the ECR discharge ion flux densities at the sample holder of several $10^{15} \mathrm{~cm}^{-2} \mathrm{~s}^{-1}$ were measured under experimental conditions similar to ours [16], whereas the average ion flux density in the GDCC chamber was approximately $10^{14} \mathrm{~cm}^{-2} \mathrm{~s}^{-1}$. Hence, the rate of damage production is lower in the DC glow discharge. Thus, it is expected that also less oxygen is required to react at these damage sites. This in turn means that the erosion rate will saturate at even lower values of $R$, however, at accordingly lower rates. Indeed, during oxygen glow discharge cleaning in ASDEX Upgrade the rate saturation was found around $0.4 \%$ [10].

\section{LABORATORY A-C:H VERSUS TOKAMAK REDEPOSITS}

The experiments reported up to this point used laboratory produced a-C:H films because they can be reproducibly prepared with predictable properties. The similarity between $\mathrm{a}-\mathrm{C}: \mathrm{H}$ and tokamak redeposits is, however, limited as the redeposits typically contain varying amounts of impurities and show structural differences. This is well demonstrated by erosion of collector samples, i. e., silicon wafer samples which had been installed in ASDEX Upgrade beneath the divertor during the 2001-2002 campaign and collected redeposited layers. For a description of similar collector samples from the 2000-2001 campaign see Ref. [24]. The collector samples were eroded in the ECR setup.

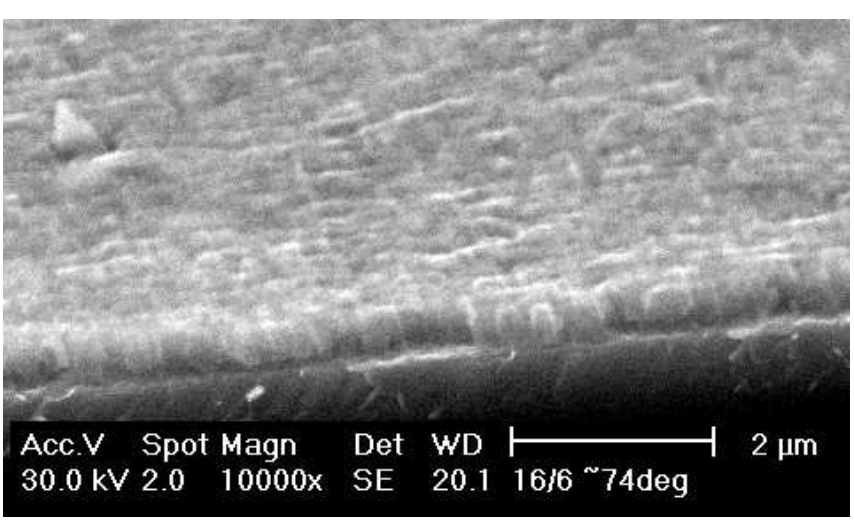

FIG. 3: Scanning electron micrograph of a co-deposited film on a Si collector substrate. The sample was broken across the middle prior to microscopy and the resulting edge is shown in the picture. The film is clearly visible on top of the underlying Si wafer. It exhibits a columnar structure and high roughness.

Figure 2 shows the ellipsometry raw data during erosion of one of the layers as large open circles. For comparison, a model curve expected for the erosion of a soft laboratorymade a-C:H film is shown. It is immediately obvious that the films are significantly different. The film was completely removed as the erosion curve ends where the ellipsometry signal for the clean Si substrate is expected. A quantitative analysis of the ellipsometry data is not possible for the ASDEX Upgrade samples. However, we can conclude that the films must be very rough, exhibit large absorption for our laser wavelength of $632.8 \mathrm{~nm}$ and possess a layered structure. One film was also investigated by scanning electron microscopy (SEM) prior to erosion. The obtained image (Fig. 3) confirms the film's high roughness and columnar structure which is very different from laboratory-produced a-C:H.

Time-resolved erosion rates could not be deduced from the ellipsometry measurements of these samples. Nevertheless, averaged erosion rates can be calculated from the total erosion times and the carbon areal densities of the co-deposited films, which are known from ion-beam analysis. The rates range from $\approx 3 \times 10^{14}$ to $\approx 3 \times 10^{15} \mathrm{~cm}^{-2} \mathrm{~s}^{-1}$ for different redeposited films. The corresponding rate for laboratory-deposited $\mathrm{a}-\mathrm{C}: \mathrm{H}$ is $\approx 5 \times 10^{15} \mathrm{~cm}^{-2} \mathrm{~s}^{-1}$ and thus roughly a factor of 2 15 higher. Additionally, the temporal evolution of the erosion rate can be roughly estimated from the time trace (not shown) of the ellipsometry raw data in Fig. 2. Erosion is initially fast, then drops to a reduced level which is almost constant for some time and then becomes especially slow in the end. Roughly $80 \%$ of the film are eroded during $20 \%$ of the total time. Nevertheless, the whole film is finally eroded. The general rate decrease with time can tentatively be explained by accumulation of impurities at the surface. In addition, the observation that the rate drops mainly in two steps suggests a layered structure.

For ASDEX Upgrade the removal of redeposited hydrocarbon layers from tungsten-coated tiles is of high relevance. Therefore, $\mathrm{W}$-coated heat shield tiles with well visible layers, removed from ASDEX Upgrade in August 2002, were 


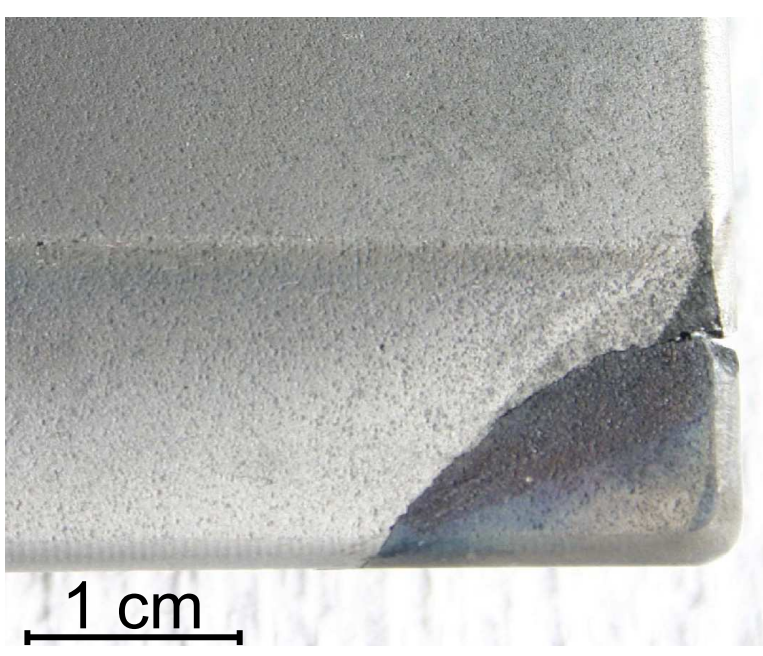

FIG. 4: Comparison of a tungsten-coated tile's surface prior to and after cleaning in a DC helium/oxygen glow discharge in GDCC. The lower right corner broke off before plasma cleaning and was not exposed to the discharge. It was glued to the tile again before taking the photograph. The layer on the corner appears dark.

exposed to the DC glow discharge plasma in the GDCC device. Figure 4 shows a direct comparison of the condition of the surface before and after erosion. Before mounting the tile in the vacuum chamber, a piece from the lower right corner in Fig. 4 broke off and was left outside the chamber during the experiment. The main part of the tile was then cleaned for 30 hours with an average ion flux density of $\approx 10^{14} \mathrm{~cm}^{-2} \mathrm{~s}^{-1}$ at $\approx 300 \mathrm{~V}$. The gas flows were $2 \mathrm{sccm}$ (standard cubic centimeters per minute) for oxygen and $20 \mathrm{sccm}$ for He resulting in a total pressure of $\approx 7 \times 10^{-3}$ mbar. The redeposited filmappearing dark - was removed and the bright metallic appearance of the tungsten surface was restored. A later examination of the layers on similar heat shield tiles by $2.5 \mathrm{MeV}^{3} \mathrm{He}^{+}$nuclear reaction analysis showed, however, that they consisted dominantly of boron, not of carbon. Hence, physical sputtering may have been their dominant erosion mechanism.

In order to quantify the erosion rates in the DC glow discharge, the amount of carbon and boron on the tungsten coating of the chosen tile was measured by Rutherford backscattering (RBS) analysis $\left(2 \mathrm{MeV}{ }^{4} \mathrm{He}^{+}\right)$before and after exposure to the plasma in various surface locations. The plasma cleaning time was chosen such that the layers would not be completely removed. The discharge parameters were adjusted to values similar to those of DC discharges in ASDEX Upgrade with an ion flux density of $\approx 10^{14} \mathrm{~cm}^{-2} \mathrm{~s}^{-1}$, $\approx 7 \times 10^{-3}$ mbar total pressure and $\approx 10 \%$ oxygen in helium. The resulting average erosion rate is $(1.1 \pm 1.0) \times 10^{13} \mathrm{C}$ and $\mathrm{B}$ atoms cm $\mathrm{cm}^{-2} \mathrm{~s}^{-1}$, meaning that it takes $\approx 100 \mathrm{~h}$ to erode one micrometer of ASDEX Upgrade deposit. The erosion rate's huge error represents the large scatter of the change in film thickness observed in the different measurement spots. This scatter probably originates from two causes, firstly from spatial variations of the film composition and, hence, real variations of the erosion rate, and secondly from slight differences in the positioning of the tile between the two RBS measure-

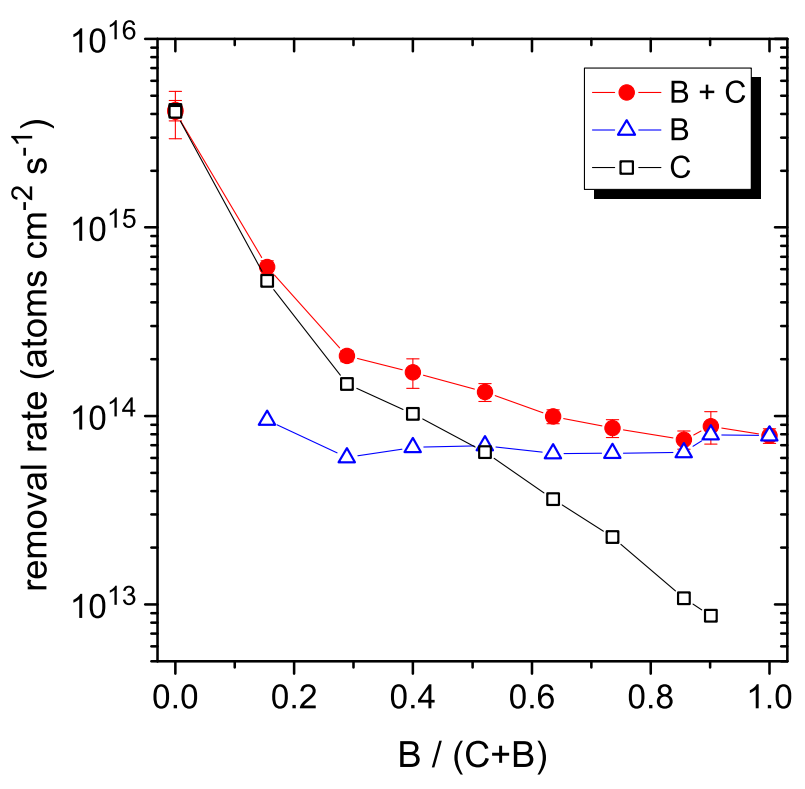

FIG. 5: Removal rates of $\mathrm{B}$ and $\mathrm{C}$ atoms from a-B:C:H films as a function of their composition in terms of the ratio $\mathrm{B} /(\mathrm{B}+\mathrm{C})$ during exposure to an oxygen discharge at a substrate bias voltage of $60 \mathrm{~V}$.

ments which may cause errors due to strong layer thickness gradients in various locations and directions.

Like the layers on the tiles removed from the inner heat shield in 2002, the redeposited layers on tiles from the same wall area removed at the time of the oxygen discharge cleaning experiment in ASDEX Upgrade after the 2004/2005 campaign [10] consisted mainly of boron with $\mathrm{C} /(\mathrm{C}+\mathrm{B})$ ratios between 0 and 0.4. Redeposits in future machines with a mix of wall materials-beryllium, tungsten and carbon in the case of ITER - will also be mixed layers with other components beside carbon and hydrogen. The oxygen discharge cleaning experiment in ASDEX Upgrade showed no cleaning effect on the boron-dominated layers [10]. Hydrogenated boron films exposed during oxygen wall cleaning in TEXTOR also showed little erosion [25].

The effect of boron on the erosion rate was studied in a laboratory experiment in more detail; a-B:C:H films with $\mathrm{B} /(\mathrm{B}+\mathrm{C})$ ratios between 0 and 1 [26] were eroded in an ECR oxygen discharge at a substrate bias voltage of $60 \mathrm{~V}$. The total erosion rate, as shown in Fig. 5, dropped by almost two orders of magnitude from pure a-C:H to pure a-B:H films. It is interesting to note that the boron erosion rate stays constant and carbon is eroded with it according to the film stoichiometry. This result can be understood in terms of impurity accumulation. Boron cannot be eroded chemically by oxygen because boron oxide $\left(\mathrm{B}_{2} \mathrm{O}_{3}\right)$ is not volatile at normal working temperatures (melting point $450^{\circ} \mathrm{C}$ and boiling point $1860^{\circ} \mathrm{C}$ [27]). Hence, carbon is preferentially eroded until a highly boron-enriched surface is formed. The erosion rate is, therefore, limited by the rate of B erosion which, in the absence of a chemically enhanced erosion mechanism, is determined by the physical sputtering yield. As even for low bulk B concen- 

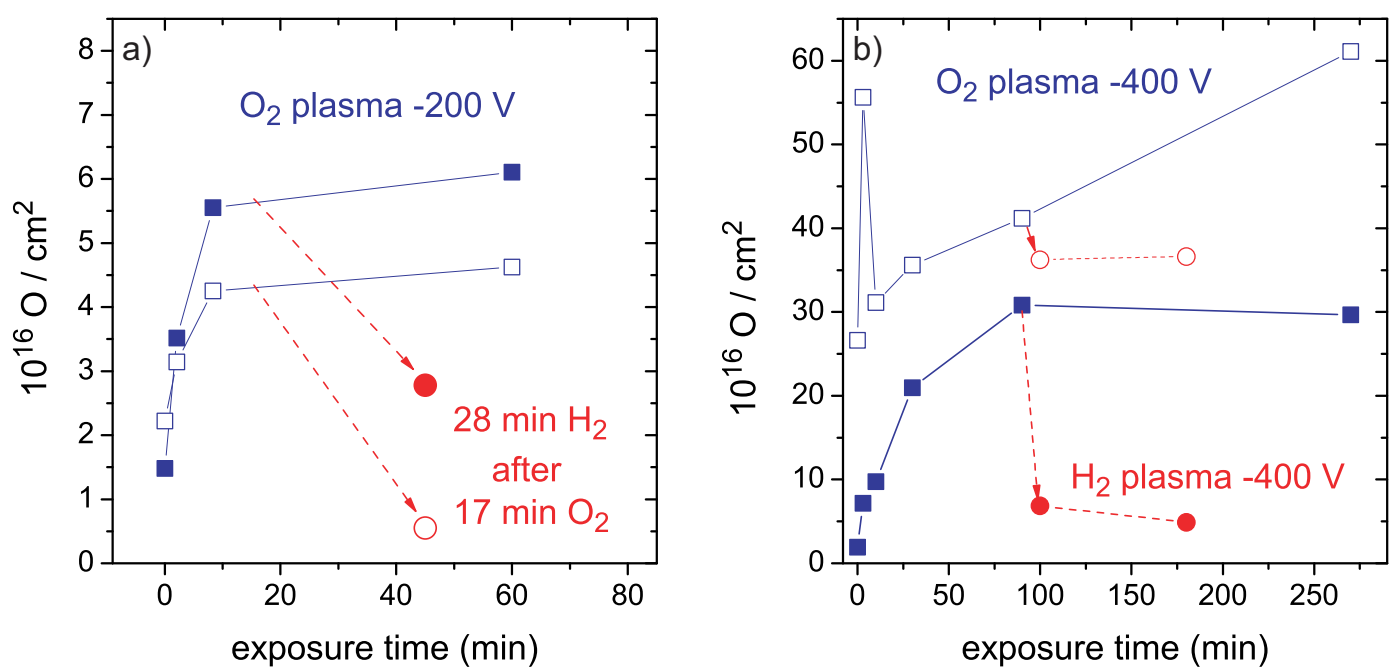

FIG. 6: Oxygen areal densities measured by NRA after treatment of polished solid tungsten (solid symbols) and tungsten coatings (open symbols) after exposure to a $\mathrm{He} / \mathrm{O}_{2}$ discharge at $-200 \mathrm{~V}$ (a) and $-400 \mathrm{~V}$ (b) bias as a function of exposure time. Some samples of each type were treated with a $\mathrm{H}_{2}$ plasma at the same bias voltage after exposure to the $\mathrm{He} / \mathrm{O}_{2}$ discharge (circles). The arrows symbolize the history of these samples.

tration an almost completely B-covered surface will develop during erosion, the $\mathrm{B}$ erosion rate $\Gamma_{\mathrm{B}}$ will be independent of the bulk B concentration. Only when boron is removed from the surface new carbon can be eroded. The carbon erosion rate $\Gamma_{\mathrm{C}}$ in steady state is determined by the film stoichiometry, i. e., $\Gamma_{\mathrm{C}}=(\mathrm{C} / \mathrm{B}) \cdot \Gamma_{\mathrm{B}}$.

\section{CLEANING EFFICIENCY ON GAP SIDE WALLS}

It is expected for ITER that a significant fraction of redeposited carbon and co-deposited tritium will be found in tile gaps [28]. It is therefore essential for the evaluation of a cleaning method to assess its suitability to clean tile gaps. For this purpose, tiles with well visible layers on the side surfaces were mounted to form a tile gap of 3 or $5 \mathrm{~mm}$ width. They were then exposed to the erosion plasma in the GDCC setup for a time interval approximately three times as long as needed for complete cleaning of the front surfaces. Afterwards the surfaces forming the gap showed no change of the interference pattern compared with that before. Obviously, the technique does not succeed in cleaning narrow gaps, most probably because the ion bombardment is not sufficient. However, it must be kept in mind that the layers contained large concentrations of boron, so that erosion was driven by physical sputtering of the boron top layer and hence by ion bombardment.

\section{COLLATERAL DAMAGE}

\section{A. Retention of oxygen}

Oxygen is a highly unwanted impurity in fusion plasmas. Hence, oxygen-containing glow discharges in a fusion experiment might raise concerns about the retention of oxygen due to implantation and formation of oxides with the first wall materials. In ASDEX Upgrade the material covering most of the glow-discharge-facing area is tungsten. Therefore, we studied the oxidation of tungsten in oxygen plasmas and its reduction by hydrogen-plasma post-treatment.

Two different types of tungsten samples were used: $1 \times$ $1 \mathrm{~cm}^{2}$ polished solid tungsten pieces and pieces of tungstencoated graphite. The latter samples were cut from test coatings produced by Plansee for ASDEX Upgrade. The layers, deposited by PVD on graphite, were $\approx 1 \mu \mathrm{m}$ thick. In each experimental run two samples, a polished and a coated one, were treated simultaneously. Oxidation was carried out in the ECR device. An ECR plasma was ignited in a mixture of $80 \% \mathrm{He}$ and $20 \% \mathrm{O}_{2}$ and an additional bias voltage of -200 or $-400 \mathrm{~V}$ was applied to the substrate holder in order to obtain ion energies similar to those in an ASDEX Upgrade DC glow discharge. Some samples were afterwards treated with a pure hydrogen discharge at the same bias voltage.

The oxygen areal density was measured by nuclear reaction analysis with $2.46 \mathrm{MeV}^{3} \mathrm{He}$. $\mathrm{A} \mathrm{SiO}_{2}$ film of known thickness on $\mathrm{Si}$ was used as calibration sample. Figure 6a shows the results of oxidation at $-200 \mathrm{~V}$. Both the polished and the coated samples show a clear increase of the oxygen density with increasing time of exposure. However, the $\mathrm{O}$ density only increases by a factor $<5$ compared to the untreated sample and starts to saturate after $\approx 10 \mathrm{~min}$. One pair of samples was treated with the $\mathrm{O}_{2}$ plasma for 17 min and afterwards with a hydrogen plasma for $28 \mathrm{~min}$. By this procedure the $\mathrm{O}$ areal density was successfully reduced to values comparable to those of the untreated samples.

Figure $6 \mathrm{~b}$ shows the corresponding data for $-400 \mathrm{~V}$ bias. Again, early saturation is seen for the polished samples, however at an oxygen areal density which is five times higher than that at $-200 \mathrm{~V}$ bias. The coated samples from the $-400 \mathrm{~V}$ bias experiments show a steady increase of the retained amount 
of $\mathrm{O}$. Where this difference in behavior between exposure at $-200 \mathrm{~V}$ and $-400 \mathrm{~V}$ bias comes from is not clear.

Hydrogen plasma post-treatment in the $-400 \mathrm{~V}$-bias experiment was done with samples which had been exposed to the oxygen plasma for 90 minutes. The $\mathrm{O}$ content of the polished samples was reduced by a factor of five after 90 minutes of $\mathrm{H}_{2}$ plasma treatment. The reduction is much less but also visible for the coatings. The reduction process is remarkably fast; there is almost no difference between 10 and 90 minutes of $\mathrm{H}_{2}$-plasma post-treatment.

The depth to which oxidation has taken place at $-200 \mathrm{~V}$ bias was determined by X-ray photoelectron spectroscopy (XPS). The spectra were recorded while the specimen was sputtered by an $\mathrm{Ar}^{+}$ion beam. The sputtering time can be converted into a scale of removed thickness using the known sputtering yield and sample density. Figure 7 shows the the oxygen signal as a function of time and the corresponding depth scale. A layer of roughly $5 \mathrm{~nm}$ is oxidized at $-200 \mathrm{~V}$ bias.

\section{B. Erosion of W, Al, Fe and C}

In the course of this work sputtering yields of aluminum and tungsten due to oxygen ion bombardment were measured in the ECR setup. Samples of Al-coated silicon and solid, polished tungsten samples, respectively, were exposed to a pure oxygen discharge with an additional bias voltage. The samples were partly covered by a piece of silicon wafer. The step height from the uncovered to the covered part of the sample was measured with a profilometer after the experiment.

In order to measure the ion current to the substrate surface, a pulsed DC voltage of $-100 \mathrm{~V}$ was applied to the sample holder via capacitive coupling. This negative voltage decayed with a constant slope as long as the ion current was in satura-

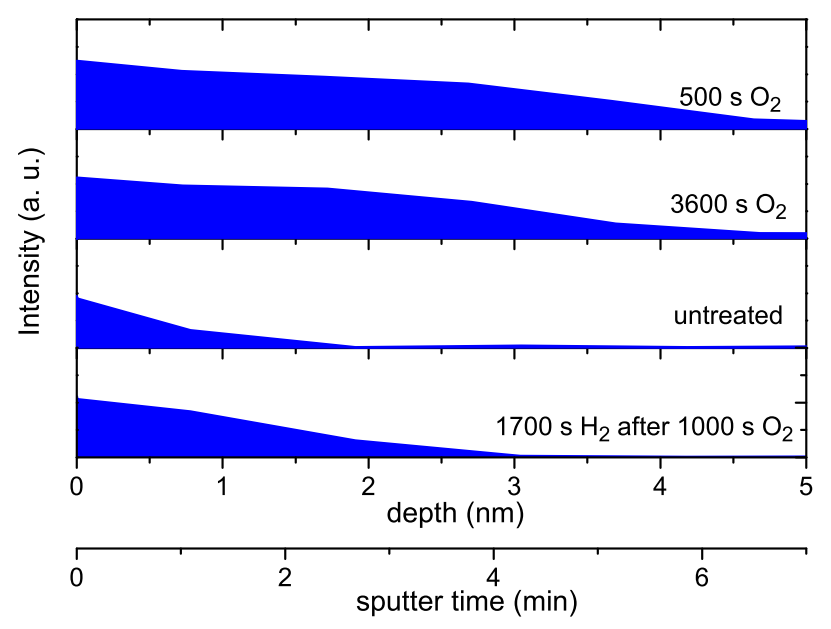

FIG. 7: XPS depth profiling of the polished tungsten samples oxidized at $-200 \mathrm{~V}$ bias. The raw signal intensities are shown in arbitrary units as a function of the sputter time and depth, respectively. tion. From this linear decay the ion flux density to the surface was determined. In order to maintain the negative bias of the substrate holder the voltage of the source was switched off after $530 \mu \mathrm{s}$ for a duration of $30 \mu \mathrm{s}$. During this period the arriving electron current neutralized the substrate holder's charge so that the time-averaged current to the substrate holder was zero.

It is known from earlier measurements under similar conditions [17] that the the total ion flux density to the wall $j_{\text {ion }}$ in the oxygen plasma is dominated by that of $\mathrm{O}_{2}^{+}$, or $j_{\text {ion }} \approx j\left(\mathrm{O}_{2}^{+}\right)$. Assuming that the molecular ions break apart into two oxygen atoms at half the energy, the sputtering yield can be approximated by

$$
Y(E)=Y(e U / 2)=\frac{\Gamma_{\text {target }}}{2 \cdot j_{\text {ion }}}
$$

where $\Gamma$ is the number of target atoms removed per $\mathrm{cm}^{2}$ and second, $U$ the bias voltage, $e$ the elementary charge and $Y_{S}(E)$ the sputtering yield of species $S$ at energy $E$.

Figure 8 shows the sputtering yields measured in this work (solid circles) together with experimental yields from the literature and calculated yields for W, Al, Fe and C. The TRIM.SP [29] calculations for $\mathrm{O} \rightarrow$ graphite, $\mathrm{O} \rightarrow \mathrm{Al}$ and $\mathrm{O} \rightarrow \mathrm{Fe}$ were performed as part of this work. The surface binding energies assumed in all calculations are $7.40 \mathrm{eV}$ for graphite, $3.36 \mathrm{eV}$ for $\mathrm{Al}, 4.34 \mathrm{eV}$ for $\mathrm{Fe}$ and $8.68 \mathrm{eV}$ for $\mathrm{W}$ [30].

For He ion bombardment the calculated yields are in reasonable agreement with measured data for any of the four target materials. The yields are between $\approx 10^{-2}$ and $\approx 10^{-1}$ in the energy region of interest between 100 and $1000 \mathrm{eV}$ except for tungsten, where they are almost by a factor of ten lower due to the greater mass and the higher surface binding energy.

For oxygen bombardment the agreement is less good due to the chemical component of the interaction. For carbon as target erosion is clearly enhanced due to chemical sputtering as can be seen in comparison with the corresponding calculated physical sputtering yield. Contrarily, the yields are reduced for $\mathrm{Al}$ and $\mathrm{W}$. This is most likely due to the formation of oxide layers which dilute the target material and increase the surface binding energies. The effect can be directly seen in Fig. 8 by comparing the sputtering yields of $\mathrm{He}$ on aluminum and aluminum oxide at lower energies. Both effects-increased chemical sputtering as well as surface oxide formation-are not included in the TRIM.SP calculations.

One potential benefit of an erosion method which at least partly relies on chemical reactions is its selectivity, i. e., a higher erosion yield for the material to be removed as compared to the substrate or other wall materials. With increasing ion energy, however, this selectivity is reduced as physical sputtering becomes more important. It is, therefore, interesting to compare the erosion yields of $\mathrm{Al}, \mathrm{W}, \mathrm{Fe}$ and graphite with the erosion yield of redeposited films obtained in the DC glow discharge (see Section IV). The discharge voltage in the experiment was $\approx 300 \mathrm{~V}$. The ion flux from the discharge consists of $\mathrm{He}^{+}, \mathrm{O}_{2}^{+}$and $\mathrm{O}^{+}$ions. The sputtering yields for $\mathrm{He}^{+}$and $\mathrm{O}^{+}$can be directly read from the graphs in Fig. 8 and the ones for $\mathrm{O}_{2}^{+}$ions as twice the yield of $\mathrm{O}^{+}$at $150 \mathrm{eV}$. The yields at $300 \mathrm{eV}$ are summarized in Table I. They are to 

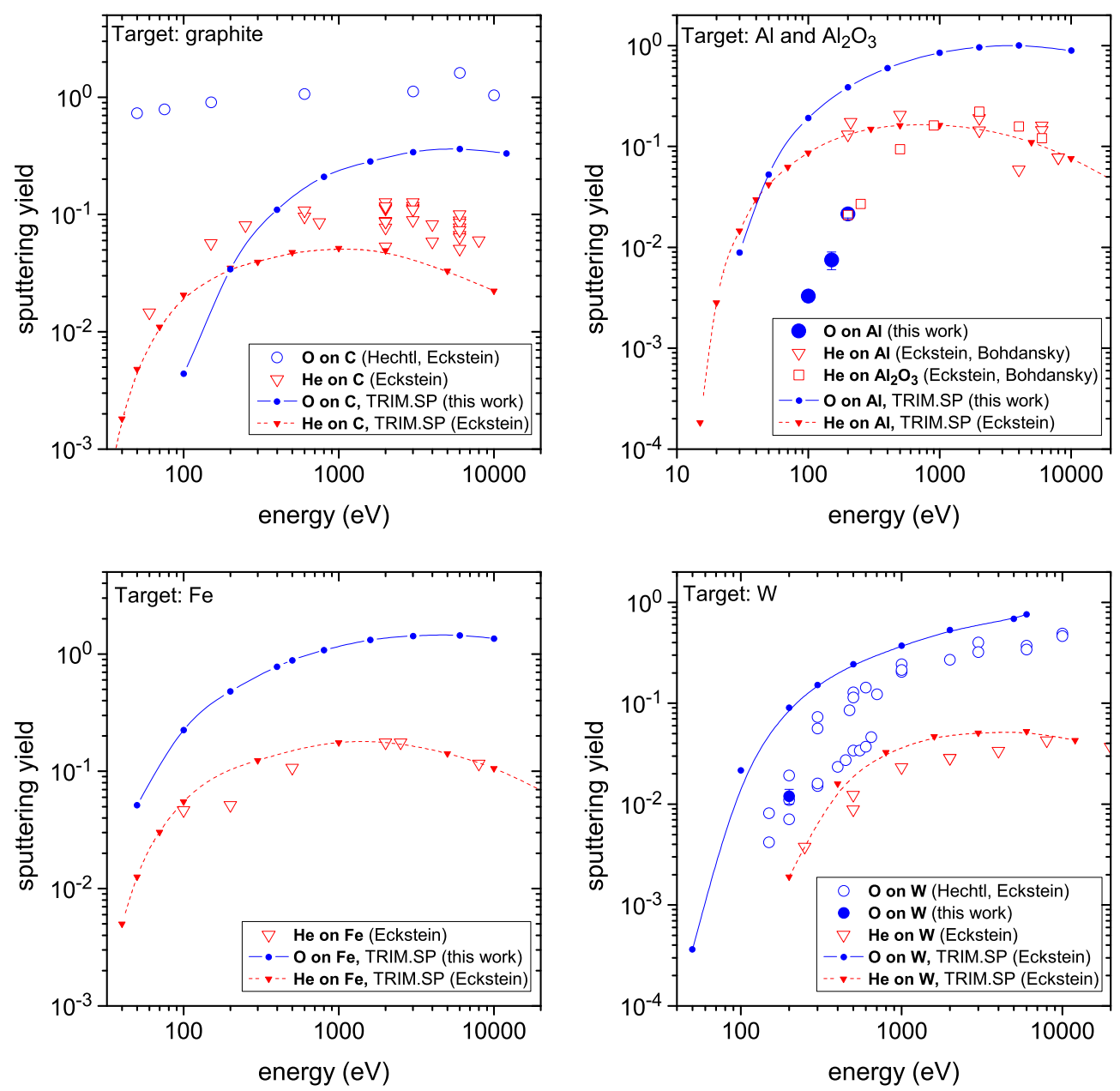

FIG. 8: Sputtering yields of graphite, aluminum, iron and tungsten under oxygen and helium bombardment. The sources of the data are: $\mathrm{O} \rightarrow \mathrm{C} \circ$ exp. [30, 31], $\mathrm{O} \rightarrow \mathrm{C}-$ calc. this work, $\mathrm{He} \rightarrow \mathrm{C} \nabla$ exp. [30], $\mathrm{He} \rightarrow \mathrm{C}--$ - calc. [30], $\mathrm{O} \rightarrow \mathrm{Al} \bullet$ exp. this work, $\mathrm{O} \rightarrow \mathrm{Al}-$ calc. this work, $\mathrm{He} \rightarrow \mathrm{Al} \nabla$ exp. [30, 32], $\mathrm{He} \rightarrow \mathrm{Al}--$ - calc. [30], $\mathrm{He} \rightarrow \mathrm{Al}_{2} \mathrm{O}_{3} \square$ exp. [30, 32], $\mathrm{O} \rightarrow \mathrm{Fe}-$ calc. this work, $\mathrm{He} \rightarrow \mathrm{Fe} \nabla$ exp. [30], $\mathrm{He} \rightarrow \mathrm{Fe}--$ - calc. [30], $\mathrm{O} \rightarrow \mathrm{W}$ 。 experimental [30, 31, 33], $\mathrm{O} \rightarrow \mathrm{W} \bullet$ exp. this work, $\mathrm{O} \rightarrow \mathrm{W}$ - calculation [30], $\mathrm{He} \rightarrow \mathrm{W} \nabla$ exp. [30], $\mathrm{He} \rightarrow \mathrm{W}---$ calc. [30]. The results of all calculations are given by the corresponding small symbols, the lines are only guides to the eye.

\begin{tabular}{llll} 
& $\mathrm{He}^{+}$ & $\mathrm{O}_{2}^{+}$ & $\mathrm{O}^{+}$ \\
\hline $\mathrm{C}$ (graphite) & 0.09 & 2 & 1 \\
$\mathrm{Al}$ & 0.04 & 0.02 & 0.05 \\
$\mathrm{Fe}$ & 0.1 & 0.8 & 0.6 \\
$\mathrm{~W}$ & 0.006 & 0.01 & 0.04
\end{tabular}

\section{Redeposition of sputtered metals}

In the GDCC setup the main part of the plasma-facing wall is stainless steel. It was found that after several hours of plasma operation with oxygen admixture brownish layers formed on the inside of the chamber windows. After extended operation the layers became thicker and it was almost impossible to look through the windows. The layers were analyzed both chemically and by X-ray fluorescence. Chemically, iron was detected in the layers using potassium thiocyanate. X-ray fluorescence showed the presence of $\mathrm{Ni}, \mathrm{Fe}$ and $\mathrm{Cr}$ and the thickness of the layer was estimated to about $10 \mathrm{~nm}$.

In order to obtain more specific information on these redeposited layers, clean pieces of a silicon wafer were laid out in the chamber during an $\mathrm{O}_{2}$-containing discharge. The film collected on the surface was then analyzed by XPS. As main constituents $\mathrm{Fe}, \mathrm{Ni}, \mathrm{Cr}$ and $\mathrm{O}$ were identified. Furthermore, the shift of the $\mathrm{Fe}$ and $\mathrm{Cr}$ peaks indicated that the two metals formed oxides. Obviously stainless steel from the wall is 
sputtered and redeposited as the metal-oxide layer.

\section{CONCLUSION}

Low-temperature oxygen plasmas have a number of unquestionable advantages regarding the removal of (hydro-)carbon layers; the rates are high compared with plasmas from alternative gases, room temperature is sufficient and the erosion products are volatile, hence easy-to-pump oxides. DC glow discharges and safety considerations may require the use of a mixture of oxygen with an inert gas, preferably helium, instead of pure oxygen. However, for typical discharge parameters this does not affect the erosion rate, as it is typically not limited by the flux of oxygen to the surface, but by the ion flux.

The erosion rate depends sensitively on the layer composition. As was shown for the case of boron as impurity in a-C:H films, the rate can drop by orders of magnitude. The mechanism for this reduction in erosion rate appears to be that boron does not form volatile oxides and can therefore only be removed by physical sputtering with low rates compared with the chemical sputtering of carbon. Preferential erosion of $\mathrm{C}$ will therefore lead to a highly boron-enriched surface which limits the steady state erosion rate. This reduction effect is to be generally expected for all impurities that do not form volatile products. For example, beryllium, the first wall material in ITER with the largest surface area, is likely to act as erosion inhibitor in this way.

One demand for the detritiation concept in ITER is that the gaps in castellated tile surfaces will be accessed too. We found that the cleaning efficiency of an oxygen DC glow discharge is not satisfactory on gap side walls, probably due to an insufficient ion flux density onto these surfaces.

While a cleaning method is intended to remove the rede- posited carbon, it should not damage the underlying wall material as well as diagnostic equipment. In this respect, the basic advantage of an erosion process that relies at least partly on chemical reactions is its selectivity. Nevertheless, oxygen plasmas might still harm other surfaces by a number of mechanisms.

Wall materials might become oxidized when in contact with the $\mathrm{O}_{2}$ discharge. For tungsten we found surface oxidation. However, the oxide layer was quickly reduced by posttreatment in a hydrogen discharge.

The chemical sputtering mechanism, which is responsible for the high rates of carbon erosion in an oxygen plasma, requires only low ion energies of several $\mathrm{eV}$. In the case of higher ion energies physical sputtering becomes important as an additional erosion mechanism which does not provide chemical selectivity. DC glow discharges typically require several hundred volts of discharge voltage, leading to ion energies of several $100 \mathrm{eV}$. All wall materials are physically sputtered at these energies of both oxygen and helium ions. For light wall materials the yields can become comparable to those of the total redeposit erosion yield. Additionally, the physically sputtered material-mostly atomic species-is likely to be redeposited in line of sight and may possibly deteriorate the properties of e. g. diagnostics mirrors. The ion energy should therefore be kept small.

\section{ACKNOWLEDGEMENT}

The authors thank C. Linsmeier and A. Wiltner for XPS measurements, S. Lindig for SEM images, J. Perchermeier for chemical analysis, M. Mayer and K. Krieger for their assistance during ion-beam analysis and various people from the ASDEX Upgrade team and the Materials-Science Technical Support for their assistance.
[1] G. Counsell, P. Coad, C. Grisola, C. Hopf, W. Jacob, A. Kirschner, A. Kreter, K. Krieger, J. Likonen, V. Philipps, J. Roth, M. Rubel, E. Salançon, A. Semerok, F. L. Tabarés, A. Widdowson, JET EFDA contributors, Plasma Phys. Control. Fusion 48 (2006) B189.

[2] R. A. Causey, J. N. Brooks, G. Federici, Fusion Eng. Des. 6162 (2002) 525.

[3] G. Federici, C. H. Skinner, J. N. Brooks, J. P. Coad, C. Grisolia, A. A. Haasz, A. Hassanein, V. Philipps, C. S. Pitcher, J. Roth, W. R. Wampler, D. G. Whyte, Nucl. Fusion 41 (2001) 1967.

[4] C. H. Skinner, C. P. Coad, G. Federici, Phys. Scripta T111 (2004) 92.

[5] W. L. Hsu, J. Vac. Sci. Technol. A 7 (1989) 1047.

[6] W. Jacob, B. Landkammer, C. H. Wu, J. Nucl. Mater. 266-269 (1999) 552.

[7] D. Mueller, W. Blanchard, J. Collins, J. Hosea, J. Kamperschroer, P. H. LaMarche, A. Nagy, D. K. Owens, C. H. Skinner, J. Nucl. Mater. 241-243 (1997) 897.

[8] J. S. Hu, J. G. Li, X. M. Wang, Y. P. Zhao, HT-7 Team, J. Nucl. Mater. 363-365 (2007) 862.

[9] V. Philipps, G. Sergienko, A. Lyssoivan, H. G. Esser,
M. Freisinger, A. Kreter, U. Samm, J. Nucl. Mater. 363-365 (2007) 929.

[10] C. Hopf, V. Rohde, W. Jacob, A. Herrmann, R. Neu, J. Roth, ASDEX Upgrade Team, J. Nucl. Mater. 363-365 (2007) 882.

[11] W. I. Urruchi, M. Massi, H. S. Maciel, C. Otani, L. N. Nishioka, Diamond Relat. Mater. 9 (2000) 685.

[12] M. Massi, R. D. Mansano, H. S. Maciel, C. Otani, P. Verdonck, L. N. B. M. Nishioka, Thin Solid Films 343-344 (1999) 381.

[13] S. Steudel, K. Myny, S. De Vusser, J. Genoe, P. Heremans, Appl. Phys. Lett. 89 (2006) 183503.

[14] K. K. Hirakuri, K. Kuwashima, K. Tatsuta, K. Sato, Diamond Relat. Mater. 14 (2005) 1067.

[15] F. Eggenstein, F. Senf, T. Zeschke, W. Gudat, Nucl. Instrum. Meth. A 467 (2001) 325.

[16] B. Landkammer, A. von Keudell, W. Jacob, J. Nucl. Mater. 264 (1999) 48.

[17] B. Landkammer, PhD Thesis, Universität Bayreuth (1999).

[18] E. Vietzke, T. Tanabe, V. Philipps, M. Erdweg, K. Flaskamp, J. Nucl. Mater. 145-147 (1987) 425.

[19] C. Hopf, M. Schlüter, W. Jacob, Appl. Phys. Lett. 90 (2007) 224106. 
[20] J. S. Hu, J. G. Li, X. M. Wang, J. Nucl. Mater. 350 (2006) 9.

[21] J. S. Hu, J. G. Li, X. M. Wang, HT-7 team, Plasma Phys. Control. Fusion 47 (2005) 1271.

[22] A. Lyssoivan, R. Koch, D. Van Eester, G. Van Wassenhove, M. Vervier, R. Weynants, M. Freisinger, A. Kreter, V. Philipps, H. Reimer, U. Samm, G. Sergienko, V. Bobkov, H.U. Fahrbach, D. Hartmann, A. Herrmann, J.-M. Noterdaeme, V. Rohde, W. Suttrop, E. Gauthier, E. de la Cal, TEXTOR Team, ASDEX Upgrade Team, J. Nucl. Mater. 363365 (2007) 1358.

[23] W. Jacob, Thin Solid Films 326 (1998) 1.

[24] M. Mayer, V. Rohde, A. von Keudell, ASDEX Upgrade Team, J. Nucl. Mater. 313-316 (2003) 429.

[25] M. J. Rubel, G. De Temmerman, G. Sergienko, P. Sundelin, B. Emmoth, V. Philipps, J. Nucl. Mater. 363-365 (2007) 877.

[26] A. Annen, M. Saß, R. Beckmann, A. von Keudell, W. Jacob, Thin Solid Films 312 (1998) 147.

[27] D. R. Lide (Ed.), CRC Handbook of Chemistry and Physics, 75th Edition, CRC Press, Boca Raton, 1994.

[28] K. Krieger, W. Jacob, D. L. Rudakov, R. Bastasz, G. Federici, A. Litnovsky, H. Maier, V. Rohde, G. Strohmayer, W. P. West, J. Whaley, C. P. C. Wong, ASDEX Upgrade Team, DIII-D Team, J. Nucl. Mater. 363-365 (2007) 870.

[29] W. Eckstein, Computer simulation of ion-solid interactions, 1st Edition, Springer Series in Materials Science, Springer Verlag, Berlin and Heidelberg, 1991.

[30] W. Eckstein, C. García-Rosales, J. Roth, W. Ottenberger, Tech. Rep. 9/82, Max-Planck-Institut für Plasmaphysik, Garching (1993).

[31] E. Hechtl, J. Bohdansky, J. Roth, J. Nucl. Mater. 103 (1981) 333.

[32] J. Bohdansky, J. Roth, F. Brossa, J. Nucl. Mater. 85-86 (1979) 1145.

[33] E. Hechtl, H. R. Yang, C. H. Wu, W. Eckstein, J. Nucl. Mater. 176-177 (1990) 874. 